\title{
The d3/fl-GH receptor gene polymorphism does not influence quality of life and body composition in GH-deficient adults receiving GH replacement therapy
}

\author{
O R Adetunji, I A MacFarlane, M Javadpour ${ }^{1}$, A Alfirevic ${ }^{2}$, M Pirmohamed ${ }^{2}$ and J C Blair ${ }^{3}$ \\ The University Department of Diabetes and Endocrinology, University Hospital Aintree, Liverpool, L9 7AL, UK, ${ }^{1}$ Walton Centre for Neurology and \\ Neurosurgery, Liverpool, L9 7LJ, UK, ${ }^{2}$ Department of Pharmacology and Therapeutics, University of Liverpool, Ashton Street, Liverpool, L69 3BX, UK \\ and ${ }^{3}$ Royal Liverpool Children's NHS Trust, Alder Hey, Liverpool, L12 2AP, UK \\ (Correspondence should be addressed to O R Adetunji; Email: o.r.adetunji@liverpool.ac.uk)
}

\begin{abstract}
Context: The growth response to recombinant human growth hormone (rhGH) in GH deficient (GHD) patients may be influenced by polymorphisms in the growth hormone receptor (GHR) gene. Objectives: To investigate adults with GHD who have been treated with rhGH for more than 1 year to determine the relationship between genomic deletion of exon 3 in the GHR gene and quality of life (QoL), body composition (BC) and serum IGF1 levels, and to compare these variables to a healthy adult control population.

Design: Cross-sectional study.

Methods: A total of 100 healthy adult controls and 131 patients were studied. Deletion of exon 3 in the GHR gene was determined in DNA that was isolated from peripheral blood. QoL was determined using the adult GHD assessment scale and three other validated QoL instruments.

Results: In the control population, the frequency of the genotypes was $53 \% \mathrm{fl} / \mathrm{fl}, 40 \% \mathrm{~d} / \mathrm{fl}$ and $7 \%$ $d 3 / d 3$, and in the patient population, 55,39 and $6 \%$ respectively. There was no significant difference in QoL scores and BC in control subjects with the $f l / f l$ genotype compared with those with the $d 3 / d 3$ or $f l / d 3$ genotype. There was no difference in the rhGH dose required to optimize serum IGF1, QoL or BC in patients with the $f l / f 1$ genotype compared with those with the $d 3 / d 3$ or d3/fl genotype.

Conclusion: Deletion of exon 3 in the GHR gene does not influence adult height, QoL or BC of the normal adult population nor does it influence rhGH dose, QoL and BC in GHD adults treated with rhGH for more than 1 year.
\end{abstract}

European Journal of Endocrinology $161541-546$

\section{Introduction}

In health, the GH receptor (GHR) is the principal regulator of GH sensitivity. The GHR consists of an extracellular domain of 246 amino acids, a single transmembrane domain and a cytoplasmic domain. The encoding gene has nine exons, but there are two isoforms of the GHR in humans generated by deletion of exon 3 of the gene resulting in three genotypes:

- full-length isoform only with retention of exon 3 on both alleles, i.e. homozygous GHRfl;

- short isoform only with exclusion of exon 3 on both alleles, i.e. homozygous $d 3$-GHR; and

- a combination of the two isoforms, i.e. heterozygous GHR-d3/fl.
Population studies have shown that the heterozygote frequency is between 25 and $40 \%$, while the GHR-d3/d3 genotype occurs in $7-15 \%$ of the population (1-4).

A number of studies in children have shown that this polymorphism may influence GH sensitivity during recombinant human $\mathrm{GH}$ (rhGH) therapy for $\mathrm{GH}$ deficiency (GHD), Turner's syndrome, idiopathic short stature and those born small-for-gestational age. Thus, subjects with the $d 3 / d 3$ or $f l / d 3$ genotype demonstrated a superior growth response during rhGH therapy compared with those with the $f l / f l$ genotype $(2,3,5,6)$. However, there are also a number of studies in similar patient populations where this association was not observed, and thus the true effect of this polymorphism on GH sensitivity in rhGH-treated children remains uncertain. It can perhaps be stated with more certainty 
that this polymorphism does not influence final adult height in healthy subjects $(4,7,8)$.

The GHD developing in adult life results in impaired quality of life (QoL) and altered body composition (BC) both of which improve with GH replacement therapy. As in children, it is now a standard practice to treat adult GHD with rhGH. To date, there are no studies investigating the effect of this common polymorphism on QoL in GHD adults. In this study, we have therefore investigated GHD adults who have been treated with rhGH for more than 1 year, in order to determine whether a relationship exists between genomic deletion of exon 3 in the GHR gene and QoL, BC and serum insulin-like growth factor-1 (IGF1) levels. We also compared these variables in healthy adult controls from the local population.

\section{Materials and methods}

\section{Patients}

Over a period of 18 months, 131 consecutive patients with GHD who consented to participate were studied. All were attending the endocrine clinic and had received rhGH treatment for more than 1 year. All were white Caucasians and all had severe GHD defined as peak GH $<9 \mathrm{mU} / \mathrm{l}$ (9) after $1 \mathrm{mg}$ s.c. glucagons $(10,11)$. The clinical history was documented from medical records. Tables 1-3 show the underlying diagnosis, demographic details and previous treatments, other medical conditions and hormone replacement.

\section{Controls}

A control group of 100 healthy white Caucasian adult volunteers from the local population were recruited for the study. The volunteers had no significant past medical history, family history of pathologic short stature and no previous or existing pituitary disease. They were assessed using the same QoL instruments as the GHD patients and their BC and GHR genotypes were also determined.

Table 1 Underlying diagnosis and previous treatment of patients with $\mathrm{GH}$ deficiency (GHD).

\begin{tabular}{lcccc}
\hline Diagnosis & Total & Surgery & Irradiation & Both \\
\hline $\begin{array}{l}\text { Non-functioning } \\
\quad \text { pituitary adenoma }\end{array}$ & 45 & 42 & 22 & 22 \\
Craniopharyngioma & 23 & 19 & 11 & 11 \\
Prolactinoma & 11 & 4 & 3 & 3 \\
Pituitary apoplexy & 4 & 1 & 0 & 0 \\
Rathke's cyst & 3 & 3 & 0 & 0 \\
Astrocytoma & 4 & 2 & 4 & 2 \\
Medulloblastoma & 4 & 4 & 4 & 4 \\
Miscellaneous & 37 & 20 & 19 & 13
\end{tabular}

Miscellaneous: Cushing's disease; acromegaly; empty sella syndrome; arachnoid cysts; chordoma; idiopathic isolated GHD; glioblastoma; thalamic tumour; meningioma; Langerhans cell histiocytosis; HSV encephalitis; pineal tumour; septo-optic dysplasia; nasopharyngeal neuroblastoma.
Table 2 Other medical conditions and hormone replacement of the GH deficiency patients $(n=131)$.

\begin{tabular}{lc}
\hline Replacement therapy & $\boldsymbol{n}(\%)$ \\
\hline Corticosteroids & $92(68 \%)$ \\
Thyroxine & $79(58 \%)$ \\
Sex hormones & $85(63 \%)$ \\
DDAVP & $28(21 \%)$ \\
Dopamine agonists & $17(13 \%)$ \\
Total hormone replcement & $20(15 \%)$ \\
Coexisting medical conditions & \\
Diabetes mellitus & \\
Hypertension & $5(4 \%)$ \\
Epilepsy & $36(27 \%)$ \\
Dyslipidaemia & $12(9 \%)$ \\
Previous CVA & $74(56 \%)$ \\
Ischaemic heart disease & $6(5 \%)$ \\
Asthma & $7(5 \%)$ \\
Obesity & $6(5 \%)$ \\
Osteoarthritis & $5(4 \%)$ \\
Anxiety/depression & $4(3 \%)$ \\
Severe COPD & $3(2 \%)$ \\
Peripheral vascular disease & $2(2 \%)$ \\
\end{tabular}

\section{Ethics}

Ethical approval was sought and obtained from the Local Research Ethics Committee for patient and control populations. Written informed consent was obtained from patients and volunteers before inclusion in the study. The study was carried out in accordance with the Declaration of Helsinki (1989) of the World Medical Association.

\section{Anthropometric measurements}

Waist-to-hip ratio (WHR) and waist circumference were measured by a single observer as previously described. Height was measured using a Harpenden stadiometer and weight was measured using electronic scales. Body mass index (BMI) and height SDS were derived from normative data from the British white Caucasian population. The percentage of body fat was measured using a bioimpedance meter (Tanita body fat analyzer model TBF-305; Tanita, Tokyo, Japan).

\section{Health-related QoL questionnaires}

QoL was assessed in both the patient and control populations using four validated questionnaires: the National Institute for Clinical Excellence (NICE) approved questionnaire for treatment of $\mathrm{GHD}$; the adult $\mathrm{GHD}$ assessment (AGHDA) questionnaire (12); the hospital anxiety and depression (HADS) questionnaire; the life fulfilment scale and the satisfaction and disease impact scale adapted for GHD patients (13). The volunteers were not required to fill in the disease impact scale questionnaire. Finally, a $10-\mathrm{cm}$ visual analogue scale (VAS) was also used to determine energy levels. The VAS scoring ranged from 0 (no energy) to $10 \mathrm{~cm}$ (full of energy). This tool has been used in previous studies of adult GHD patients (14). Higher scores are associated 
Table 3 Comparison of the measured parameters in the patients with $\mathrm{GH}$ deficiency between $d 3$ genotypes.

\begin{tabular}{llll}
\hline & \multicolumn{2}{c}{ GHR genotype } & \\
\cline { 2 - 3 } Measured variables & $f l / f l$ & $d 3 / f l$ or $d 3 / d 3$ & \\
\hline$n$ & 72 & 59 & \\
Gender (male:female) & $37: 35$ & $34: 25$ & \\
Age (years) & $49(12)$ & $51(12)$ & $\mathrm{NS}$ \\
Peak GH (mU/l) & $2.7(3.4)$ & $2.5(2.2)$ & $\mathrm{NS}$ \\
GH dose (mg) & $0.5(0.6)$ & $0.4(0.2)$ & $\mathrm{NS}$ \\
Pre-treatment IGF1 (nmol/I) & $13(5)$ & $11(4)$ & $\mathrm{NS}$ \\
Present IGF1 (nmol/l) & $26(12)$ & $26(12)$ & $\mathrm{NS}$ \\
QoL & & & \\
AGHDA & $9(6)$ & $11(7)$ & $\mathrm{NS}$ \\
HADS-depression & $6(4)$ & $7(5)$ & $\mathrm{NS}$ \\
HADS-anxiety & $6(4)$ & $7(5)$ & $\mathrm{NS}$ \\
LFSS & $42(4)$ & $41(4)$ & 0.02 \\
Satisfaction scale & $25(5)$ & $25(5)$ & $\mathrm{NS}$ \\
Disease impact scale & $26(7)$ & $24(7)$ & $\mathrm{NS}$ \\
VAS energy scale (cm) & $7.5(5)$ & $6.0(2)$ & $\mathrm{NS}$ \\
Measurements & & & \\
Height (SDS) & $-0.51(1.4)$ & $-0.23(1.2)$ & $\mathrm{NS}$ \\
BMI (SDS) & $2.06(1.1)$ & $2.25(1.0)$ & $\mathrm{NS}$ \\
WHR & $0.92(0.1)$ & $0.94(0.1)$ & $\mathrm{NS}$ \\
Body fat (\%) & $34.2(8.8)$ & $35.7(10.2)$ & $\mathrm{NS}$ \\
\hline
\end{tabular}

Significance $P<0.05$; NS, not significant. Data are presented as mean (S.D).

with worse QoL in the AGHDA questionnaire, the HADS and the satisfaction scale, and lower scores with worse QoL and energy levels in disease impact scale and VAS respectively. The order of completion of questionnaires was consistent and all questionnaires were answered in a single session.

\section{GH treatment}

Patients with multiple hormone deficiencies were adequately replaced and treatment optimized prior to commencement of rhGH according to existing national treatment guidelines (15). Treatment dose with rhGH is titrated to reference IGF1 values. All patients had also fulfilled NICE guidelines of a score $\geq 11 / 25$ on the AGHDA questionnaire before commencing treatment (9).

\section{Genotyping}

Genomic DNA was extracted from whole blood using Magnetic Bead Technology and Chemagic Magnetic Separation Module I (Chemagen, Auto Q Biosciences Ltd, Berkshire, UK) according to the manufacturer's protocol for $10 \mathrm{ml}$ blood. DNA was amplified using a multiplex strategy described by Pantel et al. (16). Briefly, $1 \mu \mathrm{l}$ of $20 \mathrm{ng} / \mu \mathrm{l}$ genomic DNA was added to $24 \mu \mathrm{l}$ reaction mixture (ReddyMix Matster Mix, ABgene, Surrey, UK) of $1.5 \mathrm{mM} \mathrm{MgCl}_{2}, 0.5 \mathrm{mM}$ each dNTP, $1 \mu \mathrm{l}$ of $0.2 \mathrm{mM}$ of each primer. The G1, G2 and G3 primers are described in GenBank accession no. AF155912. The cycling programme performed on a G-storm Thermal
Cycler PCR machine (Applied Biosystems, Foster City, CA, USA) was as follows: denaturation for $2 \mathrm{~min}$ at $94{ }^{\circ} \mathrm{C}$ followed by 35 cycles of $94^{\circ} \mathrm{C}$ for $30 \mathrm{~s}, 60^{\circ} \mathrm{C}$ for $30 \mathrm{~s}$ and $72{ }^{\circ} \mathrm{C}$ for $90 \mathrm{~s}$. This was followed by a final extension step of $7 \mathrm{~min}$ at $72{ }^{\circ} \mathrm{C}$. It was then cooled for $10{ }^{\circ} \mathrm{C}$ for $30 \mathrm{~min}$. The presence and size of amplification products were determined by electrophoresis on $1 \%$ agarose gel stained with ethidium bromide. The $f l$ allele (GHR $f$ ) is represented by a 935-bp fragment and the $d 3$ allele (d3-GHR) is represented by a 532-bp fragment. When a homozygous $d 3 / d 3$ genotype was detected (a single band corresponding to $532 \mathrm{bp}$ ) and/or when a band potentially corresponding to 935-bp product was mildly amplified, a second PCR using G1 and G3 primers was carried out, which amplified GHRfl alleles. Quality control assessment was included using both positive and negative controls in each batch of samples.

\section{Hormone measurements}

Peak serum GH levels were measured during the glucagon stimulation test (1 mg glucagon) in all GHD patients prior to commencement of therapy. Serum GH and IGF1 levels were analyzed in the hospital laboratory using chemiluminescent immunometric assays using IMMULITE 2000 (Siemens Medical Solutions Diagnostics) according to the manufacturer's instructions.

\section{Statistical analysis}

Results are expressed as percentages and mean \pm 1 S.D. The criterion for statistical significance was $P<0.05$. Differences between the variables evaluated among the d3-GHR/GHR $f$ l genotypes were calculated using ANOVA (Bonferroni). Differences for the $d 3$-GHR/GHRfl genotype frequencies were analysed by the $\chi^{2}$ test. Data were analysed using SPSS 15.0 for Windows.

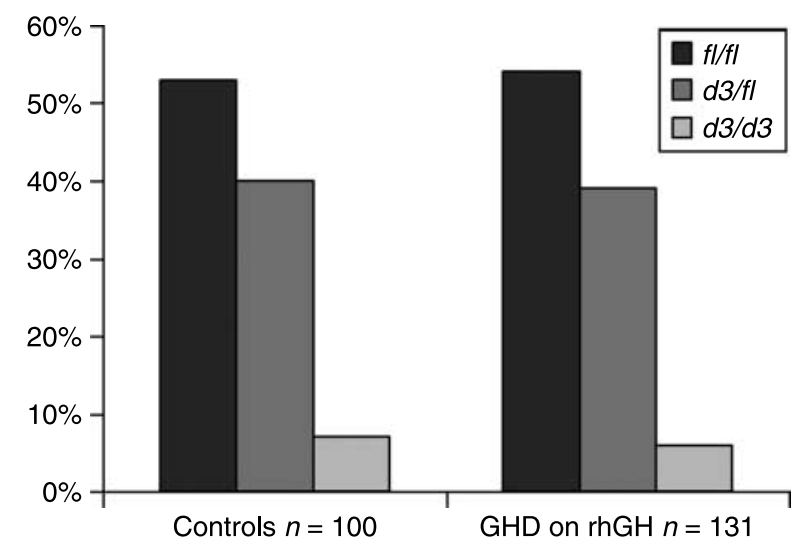

Figure 1 The frequency of the different $\mathrm{GH}$ receptor polymorphisms in the patient and control populations. 


\section{Results}

\section{Population studies and GHR-genotype frequencies}

A total of $131 \mathrm{GHD}$ patients who had been treated with rhGH for more than 1 year were studied, of whom 71 (54\%) were male. The age of the patient population was $50( \pm 12)$ years, and the mean duration since primary diagnosis in the patient population was $12( \pm 10)$ years. A total of 102 patients $(78 \%)$ had structural hypothalamic-pituitary disorders and $63(48 \%)$ of the patients had received hypothalamic irradiation. Table 1 shows the aetiology of GHD in the patients studied. Table 2 shows the coexisting medical conditions and hormone replacement therapies.

Figure 1 shows the distribution and frequency of the different genotypes in patients and controls. A total of 72 patients (55\%) were homozygous for the wild-type allele $(f l / f 1), 51(39 \%)$ patients were heterozygous for the allele coding the $\mathrm{d} 3$ isoform $(\mathrm{d} 3 / \mathrm{fl})$ and $8(6 \%)$ patients were homozygous $(d 3 / d 3)$. Of the 100 healthy adult controls, $44 \%$ were males with a mean age of $45( \pm 13)$ years. The frequency of the genotypes was $53 \%(f l / f l), 40 \%(d 3 / f l)$ and $7 \%(d 3 / d 3)$. There was no significant difference in the frequencies of these alleles between the patient and control populations.

\section{Comparison of study population between GHR genotypes}

The study populations (patients and controls) were divided into two genotype groups, with the $d 3$ homozygous and heterozygous isoforms grouped together. Comparison was made between the clinical and laboratory parameters and QoL scores between the two groups for both patients and controls. There was no

Table 4 Comparison of the measured parameters in the control population between $d 3$ genotypes.

\begin{tabular}{llll}
\hline & \multicolumn{2}{c}{ GHR genotype } & \\
\cline { 2 - 3 } Measured variables & $\mathrm{fl} / \mathrm{fl}$ & $\mathrm{d} 3 / \mathrm{fl}$ or d3/d3 & $\boldsymbol{P}$ value \\
\hline $\mathrm{N}$ & 53 & 47 & \\
Gender (male:female) & $23: 30$ & $21: 26$ & \\
Age (years) & $45(14)$ & $46(14)$ & $\mathrm{NS}$ \\
QoL & & & \\
AGHDA & $5(5)$ & $5(6)$ & $\mathrm{NS}$ \\
HADS-depression & $4(3)$ & $3(2)$ & $\mathrm{NS}$ \\
HADS-anxiety & $6(4)$ & $6(4)$ & $\mathrm{NS}$ \\
LFSS & $43(6)$ & $43(3)$ & $\mathrm{NS}$ \\
Satisfaction scale & $21(5)$ & $21(4)$ & $\mathrm{NS}$ \\
VAS energy scale (cm) & $7.1(2)$ & $7.1(2)$ & $\mathrm{NS}$ \\
Measurements & & & \\
Height (SDS) & $-0.34(1.0)$ & $-0.12(1.2)$ & $\mathrm{NS}$ \\
BMl (SDS) & $1.2(1.1)$ & $1.2(1.0)$ & $\mathrm{NS}$ \\
WHR & $0.87(0.08)$ & $0.87(0.09)$ & $\mathrm{NS}$ \\
Body fat (\%) & $29.6(9.5)$ & $30.0(9.5)$ & $\mathrm{NS}$ \\
\hline
\end{tabular}

Significance $P<0.05$; NS, not significant. Data are presented as mean (S.D).
Table 5 Comparison of the measured parameters between the GH deficiency (GHD) patients and controls.

\begin{tabular}{|c|c|c|c|}
\hline & $\begin{array}{l}\text { Controls } \\
(n=100)\end{array}$ & $\begin{array}{c}\text { GHD on } \\
\text { treatment } \\
(n=131)\end{array}$ & $P$ value \\
\hline $\begin{array}{l}\text { Gender (male:female) } \\
\text { Age (years) }\end{array}$ & $\begin{array}{l}44: 56 \\
45(13)\end{array}$ & $\begin{array}{l}71: 60 \\
50(12)\end{array}$ & 0.008 \\
\hline $\begin{array}{l}\text { QoL } \\
\text { AGHDA } \\
\text { HADS-depression } \\
\text { HADS-anxiety } \\
\text { LFSS } \\
\text { Satisfaction scale } \\
\text { VAS energy scale }(\mathrm{cm})\end{array}$ & $\begin{array}{l}5(6) \\
3(3) \\
6(4) \\
43(5) \\
21(4) \\
7.1(2.1)\end{array}$ & $\begin{array}{l}10(7) \\
7(5) \\
6(4) \\
42(4) \\
25(5) \\
5.7(2.0)\end{array}$ & $\begin{aligned}< & 0.0001 \\
<0.0001 & \text { NS } \\
& 0.02 \\
< & 0.0001 \\
< & 0.0001\end{aligned}$ \\
\hline $\begin{array}{l}\text { Measurements } \\
\text { Height (SDS) } \\
\text { BMI (SDS) } \\
\text { WHR } \\
\text { Body fat }(\%)\end{array}$ & $\begin{array}{l}-0.24(1.1) \\
1.22(1.0) \\
0.87(0.1) \\
29.8(9.5)\end{array}$ & $\begin{array}{l}-0.39(1.3) \\
2.14(1.0) \\
0.93(0.1) \\
34.9(9.5)\end{array}$ & $\begin{aligned} & N S \\
< & 0.0001 \\
< & 0.0001 \\
< & 0.0001\end{aligned}$ \\
\hline
\end{tabular}

Significance $P<0.05$; NS, not significant; Data are presented as mean (S.D). HADS, hospital anxiety and depression scale; LFSS, life fulfilment and satisfaction scale; VAS, visual analogue scale; BMI, body mass index; WHR, waist-hip ratio.

significant difference in the measured variables based on the genotype in the patient population except for the life fulfilment and satisfaction scale (LFSS) (Table 3). Similarly, in the control population, there was no difference in QoL scores and clinical parameters between the different genotypes (Table 4). Further analysis of both populations' genotypes grouped separately (i.e. $f l / f l, d 3 / f l$ and $d 3 / d 3$ ) still showed no significant difference in measured variables (not shown).

Further analysis of the volunteer population was carried out to determine the frequency of the genotypes in the extremes of height (i.e. SDS $<2.0$ and $>2.0$ ); no significant difference in the extremes of height was identified.

\section{Comparison of QoL scores between patient and control population}

Comparison of measured variables and QoL scores was undertaken between the treated GHD patients and the healthy adult controls (Table 5). There were significantly better QoL scores in the control population as compared with the patient population despite being on replacement therapy. Measurements of BMI and height were expressed in mean (S.D.) SDS for the normal adult Caucasian population. Both populations were of similar height, but the GHD patients had a significantly higher BMI and WHR than the control population.

\section{Discussion}

Despite several recent publications concerning the paediatric population, there has been very little interest in the role of polymorphisms in the GHR gene and response to GH therapy in the adult population. The only 
study investigating the exon 3 polymorphism in the adult population (17) did not address QoL, which remains the main indication for the use of rhGH in the United Kingdom. This study aimed to determine the prevalence of the polymorphism of exon 3 of the GHR in the local population and also to analyse whether a relationship exists between genotypes GHR- $d 3 / d 3$, GHR- $d 3 / f 1$ and GHR-fl/fl, and QoL, BC and serum IGF1 levels in GHD adults on stable $\mathrm{GH}$ replacement.

A total of 100 healthy Caucasian adults were studied and the prevalence of the GHR- $d 3$ polymorphisms was comparable with previous studies showing up to half of the population being homozygous for the $f$ allele. Similar frequencies were also seen in the patient population. Previous studies have shown that growth response in GHD children is greater in children who exclude exon 3 on one or both alleles compared with those who have the full length isoform on both alleles (6). Therefore, for this study, analysis was done with the genotypes GHR-fl/d3 and $d 3 / d 3$ grouped together and also separately (data not shown). We acknowledge that the low prevalence of the homozygous $\mathrm{d} 3(\mathrm{~d} 3 / \mathrm{d} 3)$ precludes proper study of this group.

Despite adequate replacement, patients on rhGH continue to have suboptimal QoL. This has been reported in previous studies showing that the QoL scores improve, but do not normalize and then plateau out after a few years on treatment $(14,18)$. This is not surprising as many of these GHD patients have had surgery and radiotherapy for intracranial pathologies and also have multiple hormone deficiencies and are receiving other hormone replacements. Also, GHD patients have a significantly higher BMI and fat mass than the control population, probably in part due to the metabolic consequences of hypothalamic-pituitary disoders $(19,20)$. Interestingly, however, these features also do not always revert to normal with hormonal replacement. As expected, there was no significant difference in the heights of the volunteers or the patients because GHD was mainly of adult onset.

Comparison was made between the different genotypes $(f 1 / f l$ vs $d 3 / f 1$ and $d 3 / d 3)$ for all the measured variables in both patients with GHD and in the control population. In the patients, this comparison included peak GH levels at diagnosis following glucagon stimulation tests, the rhGH dose required to optimize their serum IGF1 levels, their present QoL scores and BC. There was no significant difference in any of these parameters, except for the LFSS between genotypes both with $d 3$ isoform genotypes analysed together and separately. The LFSS is a scale that provides the individual with an opportunity to identify the most important areas of their lives and then 'Satisfaction with' and 'Impact on' these areas are assessed in the subsequent satisfaction and impact scales.

These data suggest that the polymorphism in exon 3 of the GHR does not influence peak GH levels during dynamic pituitary stimulation tests prior to commencement of treatment. The polymorphism also does not influence patient response to treatment as determined by their QoL scores and BC. Finally, this polymorphism did not influence the extremes of height in the control population in agreement with previous studies (21).

Other polymorphisms, such as polymorphism 504 A $>$ G at codon 168 of exon 6 and polymorphism 1576 $\mathrm{A}>\mathrm{C}$ at codon 526, are common, but do not influence response to rhGH treatment in children (7). However, the c.1319 G> T polymorphism was found to be associated with therapeutic efficacy in GHD children (22). Additionally, other genes within the GH pathway may also be important, and this relative importance may differ between adults and children. Therefore, further studies to investigate genes within and without the $\mathrm{GH}$ pathway are needed. This is important as rhGH is expensive, some patients develop adverse effects from therapy, while others show little response. Individualisation of therapy in this group of patients therefore is likely to have multiple benefits.

In conclusion, our data show that exclusion of exon 3 in the GHR gene does not influence adult height, QoL or $\mathrm{BC}$ in the normal adult control population. Similarly, in GHD adults treated with rhGH for $>1$ year, rhGH dose, QoL and BC, as well as biochemical parameters were not influenced by GH isoform expressed by the patient. Further studies in adult patients with GHD are required to determine the reasons for variability in response to rhGH.

\section{Declaration of interest}

No conflict of interest.

\section{Funding}

Unrestricted study grant by Eli Lily.

\section{Acknowledgements}

Pirmohammed M and Alfirevic A are supported by the Department of Health (UK) through the NHS Chair of Pharmacogenetics Research Programme.

\section{References}

1 Pantel J, Grulich-Henn J, Bettendorf M, Strasburger CJ, Heinrich U \& Amselem S. Heterozygous nonsense mutation in exon 3 of the growth hormone receptor (GHR) in severe GH insensitivity (Laron syndrome) and the issue of the origin and function of the GHRd3 isoform. Journal of Clinical Endocrinology and Metabolism $2003 \mathbf{8 8}$ 1705-1710.

2 Dos Santos C, Essioux L, Teinturier C, Tauber M, Goffin V \& Bougneres P. A common polymorphism of the growth hormone receptor is associated with increased responsiveness to growth hormone. Nature Genetics 200436 720-724.

3 Toyoshima MT, Castroneves LA, Costalonga EF, Mendonca BB, Arnhold IJ \& Jorge AA. Exon 3-deleted genotype of growth hormone receptor (GHRd3) positively influences IGF-1 increase at generation test in children with idiopathic short stature. Clinical Endocrinology 200767 500-504.

4 Carrascosa A, Audi L, Fernandez-Cancio M, Esteban C, Andaluz P, Vilaro E, Clemente M, Yeste D, Albisu MA \& Gussinye M. The exon 
3-deleted/full-length growth hormone receptor polymorphism did not influence growth response to growth hormone therapy over two years in prepubertal short children born at term with adequate weight and length for gestational age. Journal of Clinical Endocrinology and Metabolism 200893 764-770.

5 Binder G, Baur F, Schweizer R \& Ranke MB. The d3-growth hormone $(\mathrm{GH})$ receptor polymorphism is associated with increased responsiveness to $\mathrm{GH}$ in Turner syndrome and short small-forgestational-age children. Journal of Clinical Endocrinology and Metabolism 200691 659-664.

6 Jorge AA, Marchisotti FG, Montenegro LR, Carvalho LR, Mendonca BB \& Arnhold IJ. Growth hormone (GH) pharmacogenetics: influence of $\mathrm{GH}$ receptor exon 3 retention or deletion on firstyear growth response and final height in patients with severe $\mathrm{GH}$ deficiency. Journal of Clinical Endocrinology and Metabolism 200691 1076-1080.

7 Pilotta A, Mella P, Filisetti M, Felappi B, Prandi E, Parrinello G, Notarangelo LD \& Buzi F. Common polymorphisms of the growth hormone $(\mathrm{GH})$ receptor do not correlate with the growth response to exogenous recombinant human $\mathrm{GH}$ in $\mathrm{GH}$-deficient children. Journal of Clinical Endocrinology and Metabolism 200691 1178-1180.

8 Carrascosa A, Esteban C, Espadero R, Fernandez-Cancio M, Andaluz P, Clemente M, Audi L, Wollmann H, Fryklund L \& Parodi L. The d3/fl-growth hormone $(\mathrm{GH})$ receptor polymorphism does not influence the effect of GH treatment ( 66 microg/kg per day) or the spontaneous growth in short non-GH-deficient small-forgestational-age children: results from a two-year controlled prospective study in 170 Spanish patients. Journal of Clinical Endocrinology and Metabolism 200691 3281-3286.

9 Human growth hormone (somatropin) in adults with growth hormone deficiency. Revised July 2006. August 2003: National Institute for Clinical Excellence.

10 Leong KS, Walker AB, Martin I, Wile D, Wilding J \& MacFarlane IA. An audit of 500 subcutaneous glucagon stimulation tests to assess growth hormone and ACTH secretion in patients with hypothalamic-pituitary disease. Clinical Endocrinology $20015 \mathbf{5 4}$ 463-468.

11 Gomez JM, Espadero RM, Escobar-Jimenez F, Hawkins F, Pico A, Herrera-Pombo JL, Vilardell E, Duran A, Mesa J, Faure E \& Sanmarti A. Growth hormone release after glucagon as a reliable test of growth hormone assessment in adults. Clinical Endocrinology 200256 329-334.

12 McKenna SP, Doward LC, Alonso J, Kohlmann T, Niero M, Prieto L \& Wiren L. The QoL-AGHDA: an instrument for the assessment of quality of life in adults with growth hormone deficiency. Quality of Life Research 19998 373-383.

13 Wallymahmed ME, Baker GA, Humphris G, Dewey M \& MacFarlane IA. The development, reliability and validity of a disease specific quality of life model for adults with growth hormone deficiency. Clinical Endocrinology 199644 403-411.
14 Malik IA, Foy P, Wallymahmed M, Wilding JP \& MacFarlane IA. Assessment of quality of life in adults receiving long-term growth hormone replacement compared to control subjects. Clinical Endocrinology 200359 75-81.

15 Growth hormone deficiency (adults) - human growth hormone. In: Technical Appraisal 64. August 2003: National Institute for Clinical Excellence.

16 Pantel J, Machinis K, Sobrier ML, Duquesnoy P, Goossens M \& Amselem S. Species-specific alternative splice mimicry at the growth hormone receptor locus revealed by the lineage of retroelements during primate evolution. Journal of Biological Chemistry 2000275 18664-18669.

17 van der Klaauw AA, van der Straaten T, Baak-Pablo $\mathrm{R}$, Biermasz NR, Guchelaar HJ, Pereira AM, Smit JW \& Romijn JA. Influence of the d3-growth hormone receptor isoform on shortterm and long-term treatment response to growth hormone replacement in growth hormone deficient adults. Journal of Clinical Endocrinology and Metabolism 200893 2828-2834.

18 Wallymahmed ME, Foy P, Shaw D, Hutcheon R, Edwards RH \& MacFarlane IA. Quality of life, body composition and muscle strength in adult growth hormone deficiency: the influence of growth hormone replacement therapy for up to 3 years. Clinical Endocrinology 199747 439-446.

19 Deepak D, Furlong NJ, Wilding JP \& MacFarlane IA. Cardiovascular disease, hypertension, dyslipidaemia and obesity in patients with hypothalamic-pituitary disease. Postgraduate Medical Journal 2007 83 277-280.

20 Carroll PV, Christ ER \& Sonksen PH. Growth hormone replacement in adults with growth hormone deficiency: assessment of current knowledge. Trends in Endocrinology and Metabolism 2000 11 231-238.

21 Audi L, Esteban C, Carrascosa A, Espadero R, Perez-Arroyo A, Arjona R, Clemente M, Wollmann H, Fryklund L \& Parodi LA. Exon 3-deleted/full-length growth hormone receptor polymorphism genotype frequencies in Spanish short small-for-gestationalage (SGA) children and adolescents $(n=247)$ and in an adult control population $(n=289)$ show increased $\mathrm{fl} / \mathrm{fl}$ in short SGA. Journal of Clinical Endocrinology and Metabolism 200691 5038-5043.

22 Wan L, Chen WC, Tsai Y, Kao YT, Hsieh YY, Lee CC, Tsai CH, Chen CP \& Tsai FJ. Growth hormone (GH) receptor C.1319 $\mathrm{G}>\mathrm{T}$ polymorphism, but not exon 3 retention or deletion is associated with better first-year growth response to $\mathrm{GH}$ therapy in patients with GH deficiency. Pediatric Research 2007 62 735-740.

Received 26 June 2009

Accepted 9 July 2009 